\title{
Publicly funded homebirth in Australia: a review of maternal and neonatal outcomes over 6 years
}

\section{Christine \\ Catling-Paull \\ RN, RM, MMid \\ Lecturer in Midwifery \\ Rebecca L Coddington \\ RM, BMid(Hons), \\ PhD Candidate \\ Maralyn J Foureur \\ RM, GradDipClinEpidem, \\ Professor of Midwifery \\ Caroline S E Home \\ RM, MMedSc, PhD, \\ Professor of Midwifery \\ On behalf of the Birthplace in Australia Study and the \\ National Publicly-funded \\ Homebirth Consortium \\ Centre for Midwifery, Child and Family Health, Faculty \\ of Health, University of \\ Technology Sydney, Sydney, NSW. \\ christine.catling-paull@ uts.edu.au}

MJA 2013; 198: 616-620 doi: 10.5694/mjal2.11665

Editorial p 574 nternationally, there is ongoing debate about place of birth, ${ }^{1}$ including homebirth, ${ }^{2-5}$ birth centres, ${ }^{6,7}$ stand-alone units, ${ }^{8}$ and small maternity units. ${ }^{9}$ The debate is polarised by different professional groups with divergent views. ${ }^{10-12}$ Homebirth is explicitly endorsed in a number of countries, including Canada, the United Kingdom, the Netherlands and New Zealand, but is not endorsed in Australia. ${ }^{10}$ The main issues in Australia centre around the risks to the baby, with higher perinatal mortality rates reported in some studies of homebirth, ${ }^{13,14}$ although the evidence surrounding the safety and benefits of homebirth remains contentious. ${ }^{15-17}$ To date, no randomised controlled trials have been undertaken ${ }^{18}$ and views differ about whether this will ever be possible in the future. ${ }^{5,19}$

Homebirths account for a very small number of births in Australia. In 2010, only $0.9 \%$ of all women who gave birth had a homebirth ${ }^{20}$ compared with $2.9 \%$ in the same year in England and Wales ${ }^{21}$ and $0.6 \%$ in the US in $2006 .{ }^{22}$ A New Zealand study reported that $11 \%$ of healthy women chose to have a homebirth. ${ }^{23}$ In contrast, the Netherlands, which has a strong history of birth at home for women at low risk of complications, had a homebirth rate of around 30\% in 2004. ${ }^{24}$

Homebirth has not been a mainstream option for childbirth in Australia for many decades. In 2001, privately practising midwives providing a homebirth service were unable to obtain professional indemnity insurance owing to a collapse of the international insurance industry, and this significantly reduced the numbers of midwives who offered homebirth. These factors and a lack of government funding have meant that access to homebirth for Australian women has been extremely limited. Consumers and midwives, however, have vocally demanded such an option. ${ }^{17}$ In the recent Australian national

\section{Abstract}

Objective: To report maternal and neonatal outcomes for Australian women planning a publicly funded homebirth from 2005 to 2010.

Design, setting and subjects: Retrospective analysis of data on women who planned a homebirth and on their babies. Data for 2005-2010 (or from the commencement of a program to 2010) were requested from the 12 publicly funded homebirth programs in place at the time.

Main outcome measures: Maternal outcomes (mortality; place and mode of birth; perineal trauma; type of management of the third stage of labour; postpartum haemorrhage; transfer to hospital); and neonatal outcomes (early mortality; Apgar score at 5 minutes; birthweight; breastfeeding initially and at 6 weeks; significant morbidity; transfer to hospital; admission to a special care nursery).

Results: Nine publicly funded homebirth programs in Australia provided data accounting for $97 \%$ of births in these programs during the period studied. Of the 1807 women who intended to give birth at home at the onset of labour, 1521 (84\%) did so. 315 (17\%) were transferred to hospital during labour or within one week of giving birth. The rate of stillbirth and early neonatal death was 3.3 per 1000 births; when deaths because of expected fetal anomalies were excluded it was 1.7 per 1000 births. The rate of normal vaginal birth was $90 \%$.

Conclusion: This study provides the first national evaluation of a significant proportion of women choosing publicly funded homebirth in Australia; however, the sample size does not have sufficient power to draw a conclusion about safety. More research is warranted into the safety of alternative places of birth within Australia.

Maternity Services Review, ${ }^{25}$ more than $60 \%$ of submissions were about homebirth, with the vast majority being from women who wanted access to homebirth. ${ }^{26}$

The national review ultimately identified that homebirth was a sensitive and controversial issue. ${ }^{25}$ In particular, the review

formed the view that the relationship between maternity health care professionals is not such as to support homebirth as a mainstream Commonwealthfunded option (at least in the short term).

The release of this report in 2009 heralded the commencement of the most recent homebirth debate.

In an effort to accommodate women who wish to have a homebirth in Australia, publicly funded homebirth has been introduced by some health services in all states and territories except for Queensland, the Australian Capital Territory and Tasmania. These programs cater to women who are at low obstetric and medical risk. Professional indemnity insurance for the midwives is provided by the hospital employer, and the programs operate within the public hospital system and often are linked with, or arose from, existing birth centres or midwifery group practices. ${ }^{27}$ Midwives are usually selected to work within the programs after accreditation processes involving peer review, obstetric emergency training, ${ }^{28}$ and cannulation and suturing skills. ${ }^{27,29}$ Midwives often provide "caseload" care to a woman, which involves continuity of carer with an allocated back-up midwife. Should women develop risk factors during pregnancy or labour, the primary midwife continues care in collaboration with medical staff, and the woman's birth place changes to the birth centre or labour ward.

By 2010, there were 12 publicly funded homebirth programs in Australia. A small number of individual program evaluations have been undertaken. ${ }^{30-33}$

Studies of homebirth in Australia have raised concerns about higher perinatal mortality rates for home- 
births, but these studies have included women with risk factors, so it is difficult to draw conclusions about women at low risk. ${ }^{13,34}$ One of the significant limitations of previous studies has been the lack of data about women planning homebirth at the onset of labour, and about differing levels of risk and systems of care. $^{5,35}$ Many homebirth studies include women who planned a homebirth early in pregnancy (around 12-16 weeks). The planned place of birth can change through the pregnancy as the clinical situation changes (ie, the development of complications). Because the intended place of birth early in pregnancy does not necessarily reflect the intention at the time of birth, an analysis based on this parameter will not contribute to our understanding of neonatal safety. It is now recommended that women who transfer during pregnancy should be excluded from these analyses, and participating women should be recruited at the onset of labour. ${ }^{35}$

In 2010, we developed the National Publicly-funded Homebirth Consortium to network and share resources around the country. ${ }^{27}$ Through this consortium, we undertook a national evaluation of maternal and neonatal outcomes from publicly funded homebirth programs in Australia.

Ethics approval for the study was provided by the University of Technology Sydney Human Research Ethics Committee (HREC), and from the HRECs of the health services that were involved: the Hunter New England HREC and the South Eastern Sydney Local Health District HREC in New South Wales; the Southern Adelaide Clinical HREC and the Children, Youth and Women's Health Service HREC in South Australia; the Office of Safety and Quality in Healthcare (as an audit) in Western Australia; and the Northern Territory Department of Health and Menzies School of Health Research HREC in the NT.

\section{Methods}

Managers in charge of the 12 publicly funded homebirth programs at the time of the study (Box 1) were asked to provide routinely collected maternal and neonatal data, stored on databases

\begin{tabular}{|c|c|c|c|c|c|}
\hline State or territory* & Services included & Location & $\begin{array}{l}\text { Service } \\
\text { established }\end{array}$ & $\begin{array}{l}\text { No. booked for } \\
\text { homebirth } \\
2005-2010\end{array}$ & $\begin{array}{l}\text { Included } \\
\text { in study }\end{array}$ \\
\hline \multirow[t]{2}{*}{ Northern Territory } & Darwin Homebirth Service & Urban & 2008 & 159 & Yes \\
\hline & Alice Springs Hospital & Urban & 2010 & 63 & Yes \\
\hline \multirow[t]{5}{*}{ New South Wales } & St George Hospital & Urban & 2005 & 139 & Yes \\
\hline & Wollongong Hospital & Urban & 2009 & 20 & Yes \\
\hline & Tamworth Hospital & Rural & 2005 & 2 & Yes \\
\hline & Belmont/John Hunter Hospital & Urban & 2007 & 11 & Yes \\
\hline & Orange Aboriginal Medical Service & Rural & 2010 & 1 & No \\
\hline \multirow[t]{2}{*}{ South Australia } & Women's and Children's Hospital & Urban & 2009 & 73 & Yes \\
\hline & Lyell McEwin Hospital & Urban & 1998 & 63 & Yes \\
\hline \multirow[t]{2}{*}{ Victoria } & Sunshine Hospital & Urban & 2010 & 40 & No \\
\hline & Casey Hospital & Urban & 2010 & 14 & No \\
\hline Western Australia & Community Midwifery Program, Perth & Urban & 1996 & 1177 & Yes \\
\hline Total & & & & 1862 & 1807 \\
\hline
\end{tabular}

within the hospitals where the homebirth programs were based. Data for a period of 6 years from January 2005 to December 2010 (or from when the service began, if it had not been operating as long as 6 years) were requested. Data for all women who were planning to have a homebirth at the onset of labour were collected. Women who had planned a homebirth but were transferred to hospital-based care during pregnancy (ie, before the onset of labour) were excluded.

The data we requested included details of demographics, mode and place of birth, perineal trauma, management of the third stage of labour, postpartum haemorrhage $(>500 \mathrm{~mL})$, maternal and neonatal transfer to hospital, birthweight, maternal and neonatal morbidity and mortality, admission to a special care nursery and breastfeeding.

Any incongruity in numerical data was clarified through individual discussion with the program managers.

\section{Results}

From 2005 to 2010, a total of 1862 women intended, at the onset of labour, to have a homebirth within one of 12 publicly funded homebirth programs. Nine services provided data on 1807 women for the period requested, which accounted for $97 \%$ of the estimated publicly funded homebirths (Box 1). Three programs, accounting for 55 women, did not provide data.
Most women (1210/1805 [67\%]) were aged 26-35 years; overall, 1232/ 1807 women $(68 \%)$ were multigravid (Box 2). In total, 1521/1807 women $(84 \%)$ gave birth at home. Ninehundred and forty-five (52\%) gave birth in water. Overall, 315 women and/or their babies (17\%) were transferred to hospital during labour or within one week of giving birth; 26 gave birth in a birth centre $(1.4 \%)$, $163(9.0 \%)$ in a labour ward and 97 $(5.4 \%)$ in an operating theatre. Fifteen babies $(1 \%)$ were born before the arrival of the midwife at the woman's home (Box 3).

A total of 1807 babies were born. Almost all (1794 [99\%]) had a birthweight greater than $2500 \mathrm{~g}$. A small proportion (48 [3\%]) were admitted to the special care nursery. There were two stillbirths and four early neonatal deaths (ie, within the first week). Three of these deaths were expected because of previously diagnosed fetal anomalies, and in each of these cases the women had decided to continue with their plan to give birth at home. Details of the other deaths were not provided. The rate of stillbirth and early neonatal mortality combined was 3.3 per 1000 births. When the expected deaths of babies with fetal anomalies were excluded, the rate was 1.7 per 1000 births. Nearly all women initiated breastfeeding (1749 [97\%]); 1247 (69\%) were still breastfeeding at 6 weeks (Box 4).

Of 1807 women, 1631 (90\%) had a normal vaginal birth; 10 had breech 


\begin{tabular}{|c|c|}
\hline \multicolumn{2}{|c|}{$\begin{array}{l}2 \text { Characteristics of women in } \\
\text { Australian publicly funded } \\
\text { homebirth programs, 2005-2010 }\end{array}$} \\
\hline Characteristic & No. (\%) \\
\hline \multicolumn{2}{|c|}{ Maternal age in years $(n=1805)$} \\
\hline$\leqslant 25$ & $219(12.1 \%)$ \\
\hline $26-35$ & $1210(67.0 \%)$ \\
\hline $36-40$ & $337(18.6 \%)$ \\
\hline$>40$ & $39(2.2 \%)$ \\
\hline \multicolumn{2}{|c|}{ Gestation at birth* $(n=1807)$} \\
\hline$<37$ weeks & $19(1.1 \%)$ \\
\hline 37-42 weeks & $1754(97.1 \%)$ \\
\hline$>42$ weeks & $34(1.9 \%)$ \\
\hline \multicolumn{2}{|l|}{ Parity $(n=1807)$} \\
\hline Nullipara & 575 (31.8\%) \\
\hline Multipara & $1232(68.2 \%$ \\
\hline
\end{tabular}

*Gestation at birth determined on clinical
grounds (last menstrual period \pm early
ultrasound, as is the usual practice in
Australia).

births. Most women (999/1785 [56\%]) had an intact perineum, while $77 /$ $1785(4 \%)$ sustained a perineal graze and $610 / 1785(34 \%)$ had a first or second degree perineal tear. The episiotomy and third degree tear rates were $3 \%(47 / 1785$ women) and $1 \%$

\begin{tabular}{|c|c|}
\hline Outcomes & No. (\%) \\
\hline \multicolumn{2}{|l|}{ Place of birth $(n=1807)$} \\
\hline Home & $1521(84.2 \%)$ \\
\hline Birth centre & $26(1.4 \%)$ \\
\hline Hospital labour ward & $163(9.0 \%)$ \\
\hline Operating theatre & $97(5.4 \%)$ \\
\hline \multicolumn{2}{|l|}{ Mode of birth $(n=1807)$} \\
\hline Normal vaginal & $1631(90.3 \%)$ \\
\hline Assisted vaginal & $69(3.8 \%)$ \\
\hline Caesarean section & $97(5.4 \%)$ \\
\hline Vaginal breech & $10(0.6 \%)$ \\
\hline \multicolumn{2}{|l|}{ Perineal trauma $(n=1785)$} \\
\hline None (intact) & $999(56.0 \%)$ \\
\hline Graze & $77(4.3 \%)$ \\
\hline 1st-2nd degree tear & $610(34.2 \%)$ \\
\hline 3rd degree or more tear & $20(1.1 \%)$ \\
\hline Episiotomy & $47(2.6 \%)$ \\
\hline \multicolumn{2}{|c|}{ Management of third stage of labour $(n=1619)$} \\
\hline Expectant* & $1192(73.6 \%)$ \\
\hline Active $^{\dagger}$ & $404(25.0 \%)$ \\
\hline Manual removal & $16(1.0 \%)$ \\
\hline Not recorded & $7(0.4 \%)$ \\
\hline Postpartum haemorrhage $(n=1807)$ & $33(1.8 \%)$ \\
\hline Transfer to hospital ${ }^{\ddagger}(n=1807)$ & $315(17.4 \%)$ \\
\hline Before birth & $286(15.8 \%)$ \\
\hline After birth & $29(1.6 \%)$ \\
\hline
\end{tabular}

* Oxytocic agents were not administered prophylactically. † Including prophylactic administration of oxytocin and controlled cord traction. $\ddagger$ Includes women and/or babies (mother-infant pairs counted as one transfer)
(20/1785 women), respectively. About three-quarters of women opted for an expectant third stage of labour (1192/ 1619 [74\%]) and one-quarter had active management $(404 / 1619$ [25.0\%]). Postpartum haemorrhage occurred in 33/1807 women (2\%) (Box 3). There were no maternal deaths.

\section{Discussion}

This study contributes to the evidence about homebirth as an option for women at low obstetric risk. The rate of stillbirth and early neonatal mortality, when excluding deaths of babies with fetal anomalies, was low, at 1.7 per 1000 births. The maternal and neonatal outcomes in this study are comparable with other studies of homebirth for lowrisk women. ${ }^{36-38}$

Most studies of homebirth in other countries have found no statistically significant differences in perinatal outcomes between home and hospital births for women at low risk of complications. ${ }^{36,37,39}$ However, a recent study in the United States showed poorer neonatal outcomes for births occurring at home or in birth centres. ${ }^{40} \mathrm{~A}$ meta-analysis in the same year demonstrated higher perinatal mortality associated with homebirth ${ }^{41}$ but has been strongly criticised on methodological grounds. ${ }^{5,42}$ The Birthplace in England study, ${ }^{43}$ the largest prospective cohort study on place of birth for women at low risk of complications, analysed a composite outcome, which included stillbirth and early neonatal death among other serious morbidity. Among 64538 low-risk women, of whom more than 16000 planned a homebirth at the onset of labour, no difference was found in the adjusted odds between obstetric units and other birthplaces, including homebirth. However, higher rates of a composite outcome of perinatal morbidity and mortality were seen for nulliparous women having homebirths (adjusted odds ratio 1.75 ; $95 \% \mathrm{CI}, 1.07-2.86$ ), with no differences for multiparous women. Interventions during labour were substantially lower at home, although transfer rates to hospital, especially for nulliparous women, were high.
Our study found a normal vaginal birth rate of $90 \%$. This concurs with the Birthplace in England study, ${ }^{43}$ which showed a higher rate of normal vaginal birth when women gave birth outside of a hospital environment. Interestingly, there were 10 vaginal breech births in the planned homebirth group in our study. Breech is usually considered a contraindication to homebirth and was not one of the inclusion criteria for the publicly funded homebirth programs in our study. The rate of breech birth was low $(0.6 \%)$ and is likely to have been undiagnosed, necessitating transfer to hospital during labour. We do not have more detailed information on these births.

The intrapartum hospital transfer rates of women in our study are also comparable with others. ${ }^{36,38,44}$ Fewer than one in five women were transferred to hospital during labour or within 1 week of giving birth because of factors necessitating medical care. Future analyses need to be able to report transfer rates by parity as it is known that nulliparous women have higher transfer rates.

Of interest was the rate of postpartum haemorrhage in this cohort of women. Most women (74\%) had expectant management of the third stage of labour, and one-quarter had active management. Active management is the more common practice in hospital settings. Despite the lower than usual rates of active management of the third stage in the homebirth cohort, only $2 \%$ had a postpartum haemorrhage, similar to the rates found among women cared for in midwifery models of care, ${ }^{45,46}$ but lower than NSW population data. ${ }^{47}$ Postpartum haemorrhage rates in hospital settings are reported to be $6.3 \%,{ }^{47}$ although a proportion of these women would be at high risk. Recent data from the UK have also shown significantly lower rates of postpartum haemorrhage in women having a homebirth. ${ }^{48}$

The low emergency caesarean section rate and assisted vaginal birth rate in our study were consistent with the low rate of caesarean section $(2.8 \%)$ recorded in the Birthplace in England Study for women who planned a homebirth ${ }^{43}$ and in a South Australian study $(9.2 \%$ for planned homebirths v 
$27.1 \%$ for hospital births). ${ }^{13} \mathrm{~A}$ low rate of caesarean section is also consistent with studies of homebirth in the US. ${ }^{36}$

In our study, over half the women who gave birth at home did so in water. Many labour wards do not have this as an option; however, use of water in labour and birth is currently a strategy to promote normal birth. ${ }^{49}$

Women in our study had a high rate of breastfeeding at 6 weeks postpartum (69\%) compared with other Australian data showing that $58 \%$ of all infants were fully breastfed at 2 months of age. ${ }^{50}$ This may have been owing to a higher motivation of women in our cohort, and a good level of support and continuity of midwifery care, which has been shown to enhance rates of breastfeeding.

The outcomes in our study may be due to the strict eligibility criteria for women to access a publicly funded homebirth. ${ }^{27}$ Mostly, women eligible for a publicly funded homebirth have a singleton pregnancy, are within 3742 weeks' gestation, have no medical, surgical or obstetric risk factors and have normal pregnancies. The homebirth program midwives work within local policies that are guided by strict state and professional organisation policies. ${ }^{51-53}$ The strict criteria for women to be able to access a publicly funded homebirth program promote safety and minimise the need for transfer to hospital. This is reflected in the low rates of hospital transfer and intervention in this study.

The strength of this study is that all data were sourced from publicly funded homebirth services in Australia. Many previous studies in this country have combined homebirth data from women who have had highrisk pregnancies, ${ }^{13,54}$ and some have had questionable data collection methods. ${ }^{14}$ One limitation is that only nine of the 12 programs established at the time of the study provided data, although these nine account for $97 \%$ of all births in publicly funded programs. There were no major differences between elements of the participating homebirth services and the services that did not provide data. It is not known whether inclusion of data from the three programs that did not participate would significantly change the findings. One of these services was very small, having sup- ported only one woman. The other two were having their own internal evaluations occurring at this time, which took priority. One of these has since been published ${ }^{32}$ and showed few adverse events and no perinatal deaths among 14 women planning homebirths, which suggests that the outcomes of our study would not have been worse if they had been included.

A further limitation of the study is that we did not collect data on reasons for transfer to hospital during labour, or the parity of the women transferred. This would have been useful for determining whether women were transferred for medical care or simply for pain relief. Also, we did not formally collect neonatal data up to 28 days, but used data entered by midwives in the early neonatal period, and we did not request details on the babies who were stillborn or who died in the early neonatal period. Given the close, local scrutiny of these programs, it is highly likely that any later adverse outcomes would have been reported. "Self-selection" is a limitation that applies to any study of women who choose to give birth at home. This is likely to be similar in this study, although limited demographic data were obtained.

Our study is the first evaluation to include a significant proportion of all women who chose publicly funded homebirth in Australia. Rates were low for caesarean section, postpartum haemorrhage, third degree perineal tears, stillbirth and early neonatal death in this sample of women and babies. However, the sample size does not have sufficient power to allow us to draw any conclusions about safety. More research is warranted into the safety and costs of alternative places of birth within Australia.

Acknowledgements: We acknowledge and thank the members of the National Publicly-funded Homebirth Consortium. The Chief Investigators of the Birthplace in Australia Study are: Caroline Homer, Maralyn Foureur and David Sibbritt (University of Technology Sydney); David Ellwood (Australian National University); Jeremy Oats (University of Melbourne); Della Forster and Helen McLachlan (La Trobe University); and Hannah Dahlen (University of Western Sydney). This study was part of the Birthplace in Australia Study, funded through a National Health and Medical Research Council Project Grant (20122015).

\section{Competing interests: No relevant disclosures.}

Received 12 Nov 2012, accepted 26 Apr 2013.

1 Ellwood D. The debate about place of birth. Aust N Z J Obstet Gynaecol 2008; 48: 449.

2 Dahlen HG, Homer CSE, Tracy SK, Bistis AM. Planned home and hospital births in South
4 Neonatal outcomes for babies of women in Australian publicly funded homebirth programs, 2005-2010 $(n=1807)$

Outcome

No. (\%)

Survival and mortality

Live

1805 (99.9\%)

Stillborn

$4(0.2 \%)$

Early neonatal death (within first week after birth)

Apgar score $<7$ at 5 minutes

$13(0.7 \%)$

Birthweight

$<2.5 \mathrm{~kg}$

$13(0.7 \%)$

$2.5-4 \mathrm{~kg}$

$1386(76.7 \%)$

$>4 \mathrm{~kg}$

$408(22.6 \%)$

Admission to special care nursery

$48(2.7 \%)$

Neonatal morbidity

Respiratory distress

$7(0.4 \%)$

Hypoxic-ischaemic encephalopathy

$2(0.1 \%)$

Infant feeding

Initiation of breastfeeding

$1749(96.8 \%)$

Breastfeeding at 6 weeks

$1247(69.0 \%)$

Australia, 1991-2006: differences in outcomes [letter]. Med J Aust 2010; 192: 726-727.

3 Health Legislation Amendment (Midwives and Nurse Practitioners) Bill 2009. Canberra: Commonwealth of Australia, 2009.

4 Sweet M. The AMA says we are "shooting the messenger" re homebirth critique. Croakey: the Crikey health blog. 21 Jan 2010. http://blogs. crikey.com.au/croakey/2010/01/21/the-amasays-we-are-shooting-the-messenger-rehomebirth-critique (accessed Mar 2013).

5 Keirse MJ. Home birth: gone away, gone astray, and here to stay. Birth 2010; 37: 341-346.

6 Laws PJ, Lim C, Tracy S, Sullivan EA. Characteristics and practices of birth centres in Australia. Aust N Z J Obstet Gynaecol 2009; 49: 290-295.

7 Tracy SK, Dahlen H, Laws P, et al. Birth centers in Australia: a national population-based study of perinatal mortality associated with giving birth in a birth center. Birth 2007; 34: 194-201.

8 Tracy SK, Hartz D, Nicholl M, et al. An integrated service network in maternity - the implementation of a midwifery-led unit. Aust Health Rev 2005; 29: 332-339.

9 Tracy S, Sullivan E, Dahlen H, et al. Does size matter? A population based study of birth in lower volume maternity hospitals for low risk women. BJOG 2006; 113: 86-97.

10 Royal Australian and New Zealand College of Obstetricians and Gynaecologists. Home births. College Statement: C-Obs 2. Melbourne: RANZCOG, 2009. http://www.ranzcog.edu.au/ component/docman/doc_view/936-c-obs-02home-births.html (accessed Feb 2013).

11 Australian College of Midwives. Maternity Services Review submissions. Submission 380. Canberra: Department of Health and Ageing, 2008.

12 Royal College of Obstetricians and Gynaecologists, Royal College of Midwives. Home births. Joint statement No. 2, April 2007. London: RCOG and RCM, 2007. http://www.rcog.org.uk/ files/rcog-corp/uploaded-files/JointStatment HomeBirths2007.pdf (accessed May 2013).

13 Kennare RM, Keirse MJ, Tucker GR, Chan AC. Planned home and hospital births in South Australia, 1991-2006: differences in outcomes. Med J Aust 2010; 192: 76-80.

14 Bastian H, Keirse MJ, Lancaster PA. Perinatal death associated with planned home birth in Australia: population based study. BMJ 1998; 317 384-388. 
15 Pesce A. Planned homebirths in Australia: art science or politics? O\&G Magazine 2009; 11 : 29-30.

16 Pesce AF. Planned home birth in Australia: politics or science? [editorial]. Med J Aust 2010; 192: 60.

17 Newman LA. Why planned attended homebirth should be more widely supported in Australia. Aust N Z J Obstet Gynaecol 2008; 48: 450-453.

18 Olsen O, Clausen JA. Planned hospital birth versus planned home birth. Cochrane Database Syst Rev 2012; (9): CD000352.

19 McLachlan H, Forster D. The safety of home birth: is the evidence good enough? CMAJ 2009; 181: 359-360.

20 Li Z, Zeki R, Hilder L, Sullivan EA. Australia's mothers and babies 2010. Canberra: Australian Institute of Health and Welfare National Perinatal Epidemiology and Statistics Unit, 2012. (AlHW Cat. No. PER 57: Perinatal Statistics Series No. 27.) http://www.aihw.gov.au/WorkArea/ DownloadAsset.aspx?id=60129542372 (accessed May 2013).

21 Live births in England and Wales by characteristics of birth, 2010. UK: Office for National Statistics. http://www.ons.gov.uk/ons/ dcp171778_241936.pdf (accessed Oct 2012)

22 MacDorman MF, Declerca E, Mathews TJ. United States home births increase 20 percent from 2004 to 2008. Birth 2011; 38: 185-190.

23 Davis D, Baddock S, Pairman S, et al. Planned place of birth in New Zealand: does it affect mode of birth and intervention rates among low-risk women? Birth 2011; 38: 111-119.

24 EURO-PERISTAT project; SCPE, EUROCAT, EURONEONET. European perinatal health report. 2008. http://www.europeristat.com (accessed May 2013)

25 Australian Government Department of Health and Ageing. Improving maternity services in Australia. Report of the Maternity Services Review. Canberra: Commonwealth of Australia, 2009. http://www.health.gov.au/internet/main/ publishing.nsf/Content/maternityservices review-report (accessed May 2013)

26 Dahlen H, Jackson M, Schmied V, et al. Birth centres and the National Maternity Services Review: response to consumer demand or compromise? Women Birth 2011; 24:165-172.

27 Catling-Paull C, Foureur MJ, Homer CS. Publiclyfunded homebirth models in Australia. Women Birth 2012; 25: 152-158.

28 ALSO. Advanced life support in obstetrics [website]. http://www.also.net.au (accessed Mar 2013).

29 Homer C, Caplice S. Evaluation of the publiclyfunded homebirth program in South East Sydney Illawarra Area Health Service. September 2007. Sydney: Centre for Midwifery, Child and Family
Health, Faculty of Nursing, Midwifery and Health, University of Technology Sydney, 2007.

30 McMurtrie J, Catling-Paull C, Teate A, et al. The St George Homebirth Program: an evaluation of the first 100 booked women. Aust N Z J Obstet Gynaecol 2009; 49: 631-636.

31 Thiele B, Thorogood C. Community based midwifery program in Fremantle WA. Fremantle: Centre for Research for Women and the Fremantle Community Midwives, 1997.

32 Hider K. Evaluation of the Casey Hospital Home Birth Pilot. Melbourne: Centre for Clinical Effectiveness, Southern Health, 2011.

33 Nixon A, Bryne J, Church A. The Community Midwives Project: an evaluation of the set-up of the Northern Women's Community Midwives Project. June 1998 - November 2000. Adelaide: Northern Metropolitan Community Health Service, 2003.

34 Bastian H. Commentary: Why are researchers surprised when there is not a smooth transition from research into practice? BMJ 1998; 317: 1230.

35 Gyte G, Dodwell M, Newburn M, et al. Estimating intrapartum-related perinatal mortality rates for booked home births: when the 'best' available data are not good enough. BJOG 2009; 116: 933-942.

36 Johnson KC, Daviss BA. Outcomes of planned home births with certified professional midwives: large prospective study in North America. BMJ 2005; 330: 1416-1422

37 de Jonge A, van der Goes BY, Ravelli AC, et al. Perinatal mortality and morbidity in a nationwide cohort of 529,688 low-risk planned home and hospital births. BJOG 2009; 116 : $1177-1184$.

38 Murphy PA, Fullerton J. Outcomes of intended home births in nurse-midwifery practice: a prospective descriptive study. Obstet Gynecol 1998; 92: 461-470.

39 Janssen PA, Saxell L, Page LA, et al. Outcomes of planned home birth with registered midwife versus planned hospital birth with midwife or physician. CMAJ 2009; 181: 377-383.

40 Wax JR, Pinette MG, Cartin A, Blackstone J. Maternal and newborn morbidity by birth facility among selected United States 2006 low-risk births. Am J Obstet Gynecol 2010; 202: el-e5.

41 Wax JR, Lucas FL, Lamont M, et al. Maternal and newborn outcomes in planned homebirth vs planned hospital births: a metaanalysis. Am J Obstet Gynecol 2010; 203: el-e8.

42 Vedam S, Janssen PA, Lichtman R. Science and sensibility: choice of birth place in the United States. Medscape News [internet] 2010; 25 Feb. http://www.medscape.com/viewarticle/717516 (accessed Jan 2013).

43 Birthplace in England Collaborative Group, Brocklehurst P, Hardy P, Hollowell J, et al. Perinatal and maternal outcomes by planned place of birth for healthy women with low risk pregnancies: the Birthplace in England national prospective cohort study. BMJ 2011; 343: d7400. doi: 10.1136/bmi.d7400.

44 Lindgren HE, Hildingsson IM, Christensson K, Rådestad IJ. Transfers in planned home births related to midwife availability and continuity: a nationwide population-based study. Birth 2008; 35: 9-15.

45 Hatem M, Sandall J, Devane D, et al. Midwife-led versus other models of care for childbearing women. Cochrane Database Syst Rev 2008; (4): CD004667.

46 Fahy K, Hastie C, Bisits A, et al. Holistic physiological care compared with active management of the third stage of labour for women at low risk of postpartum haemorrhage: a cohort study. Women Birth 2010; 23: 146-152.

47 Cameron CA, Roberts CL, Olive EC, et al. Trends in postpartum haemorrhage. Aust N Z J Public Health 2006; 30: 151-156.

48 Nove A, Berrington A, Matthews Z. Comparing the odds of postpartum haemorrhage in planned home birth against planned hospital birth: results of an observational study of over 500,000 maternities in the UK. BMC Pregnancy Childbirth 2012; 12:130.

49 NSW Health. Maternity - towards normal birth in NSW. [Policy directive.] Sydney: NSW Health, 2010. http://www0.health.nsw.gov.au/policies/ pd/2010/pdf/PD2010 045.pdf (accessed May 2013).

50 Australian Bureau of Statistics. Australian Health Survey: health service usage and health related actions, 2011-2012. Canberra: ABS, 2013. (ABS Cat. No. 4364.0.55.002.) http://www.abs.gov. au/ausstats/abs@.nsf/Lookup/6664B939E49 FD9CICA257B39000F2E4B?opendocument (accessed Apr 2013)

51 Australian College of Midwives. National midwifery guidelines for consultation and referral. 2nd ed. Canberra: ACM, 2008. http:// midwives.rentsoft.biz/lib/pdf/Consultation\%20 and\%20Referral\%20Guidelines\%202010.pdf (accessed Mar 2013).

52 Government of South Australia. Policy for planned birth at home in South Australia. 4 July 2007. Adelaide: South Australian Department of Health, 2007. http://www.health.sa.gov.au/PPG/ Portals/0/planned home birth policy SA.pdf (accessed May 2013).

53 NSW Health. Maternity - public homebirth services. [Policy directive.] Sydney: NSW Health, 2006. http://www0.health.nsw.gov.au/policies/ pd/2006/pdf/PD2006_045.pdf (accessed May 2013)

54 Crotty M, Ramsay AT, Smart R, Chan A. Planned homebirths in South Australia 1976-1987. Med J Aust 1990; 153: 664-671.

\section{Make a big splash and dive head first into the MJA Christmas Competition}

Let our readers share the experience of your unusual and humorous medical stories. Send us your strange images, cartoons, quirky quips and gory stories. You can win great prizes AND be published in the MJA Australia's premier medical journal.

For full submission details visit: https://www.mja.com.au/journal/ mja-instructions-authors

Contact our Editorial Administrator Phone: 0295626666

Email:mja@mja.com.au

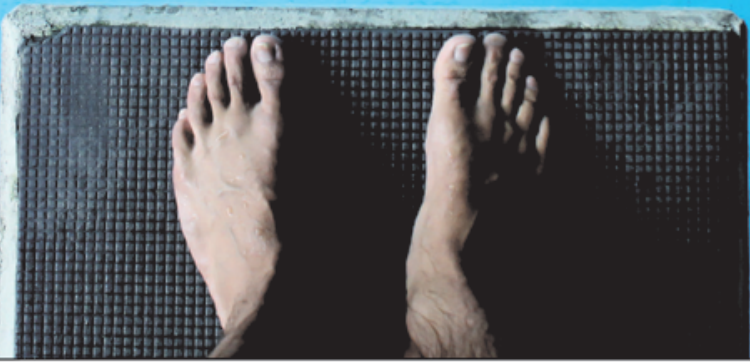

Entries close:

Friday 11 October 2013

Visit last year's winners at: https://www.mja.com.au/ journal/2012/197/11/earthpeace-and-good-will-andfair-go-all 